\title{
Quality of life and mortality from a nephrologist's view: a prospective observational study \\ Seung Seok Han' ${ }^{1}$ Ki Woong Kim², Ki Young Na1,4, Dong-Wan Chae ${ }^{1,3,4}$, Yon Su Kim ${ }^{1,3}$, Suhnggwon Kim ${ }^{1,3}$ and Ho Jun Chin*1,3,4
}

Address: ${ }^{1}$ Department of Internal Medicine, Seoul National University College of Medicine, Seoul, Korea, ${ }^{2}$ Department of Psychiatry, Seoul National University College of Medicine, Seoul, Korea, ${ }^{3}$ Kidney Research Institute, Seoul National University College of Medicine, Seoul, Korea and ${ }^{4}$ Department of Internal Medicine, Seoul National University Bundang Hospital, Gyeonggi-do, Korea

Email: Seung Seok Han - hansway@medimail.co.kr; Ki Woong Kim - kwkimmd@snu.ac.kr; Ki Young Na - kyna@snubh.org; DongWan Chae - cdw1302@snubh.org; Yon Su Kim - yonsukim@snu.ac.kr; Suhnggwon Kim - skimim@plaza.snu.ac.kr;

Ho Jun Chin* - mednep@snubh.org

* Corresponding author

Published: 24 November 2009

BMC Nephrology 2009, 10:39 doi:10.1186/147|-2369-10-39
Received: 2I August 2009

Accepted: 24 November 2009

This article is available from: http://www.biomedcentral.com//47/-2369/10/39

(C) 2009 Han et al; licensee BioMed Central Ltd.

This is an Open Access article distributed under the terms of the Creative Commons Attribution License (http://creativecommons.org/licenses/by/2.0), which permits unrestricted use, distribution, and reproduction in any medium, provided the original work is properly cited.

\begin{abstract}
Background: Although health-related quality of life (HRQOL) is a potential independent predictor of mortality, nephrologists have shown little interest in HRQOL with respect to mortality in chronic kidney disease (CKD). The aim of this article is to evaluate the impact of HRQOL on mortality in the elderly, who are likely to develop or already have CKD.
\end{abstract}

Methods: Among 1,000 randomly sampled participants aged more than 65 years (sourced from the Korean Longitudinal Study on Health and Ageing), 944 subjects were evaluated for HRQOL. HRQOL was assessed using a 36-item Short-Form health survey (SF36). A cumulative survival rate was calculated according to tertiles of SF36 scores and classified by the presence of CKD (estimated GFR $<60 \mathrm{ml} / \mathrm{min} / 1.73 \mathrm{~m}^{2}$ ).

Results: Among 944 subjects, $46.6 \%$ had CKD. CKD patients had lower total and physical component scores compared with subjects without CKD. The 3-year cumulative survival rate was $90.0 \%$ (non-CKD vs. CKD: $92.6 \%$ vs. $87.4 \%, P=0.005$ by log rank test). After adjusting for multiple variables, a reduced SF36 score (physical and mental components) was a strong predictor of allcause mortality. Physical components were consistently able to predict mortality after CKD classification, but mental components were statistically significant only in the CKD group.

Conclusion: In addition to traditional risk factors of mortality, nephrologists should be aware of HRQOL as a predictor of mortality and should make efforts to improve HRQOL in CKD patients.

\section{Background}

"The aging society" is a familiar term as elderly individuals (aged 65 years and older) make up an increasing proportion of the global population [1]. In line with global trends, the proportion of the elderly in Korea is increasing
(8.3\% in 2003) and is expected to reach $15 \%$ in 2019 [2]. This increase may lead to age-associated increases in chronic diseases. Chronic kidney disease (CKD) has been recognized as one of a number of chronic diseases primarily affecting the elderly. Worldwide, the prevalence of 
CKD in the elderly has increased to nearly half of the population aged 70 years and older [3], and the incidence among the elderly in Korea is similar [4]. Therefore, the problems associated with CKD need to be appropriately managed to reduce the burden of CKD in the aging society.

The ability to predict future morbidity and mortality is a key to reduce the burden of CKD. To this end, monitoring a patient's functional and subjective status of well-being, collectively known as health-related quality of life (HRQOL), is of particular importance in CKD patients [47]. Traditional risk factors (e.g., atherosclerosis, smoking, and diabetes mellitus) for mortality had been considered important in the elderly with or without CKD $[8,9]$; however, it is currently thought that traditional risk factors do not account for all reported mortality [10]. Recently, HRQOL, comprising physical, mental, and social health, is recognized as an important predictor of mortality in elderly individuals or patients with end-stage renal disease $[5,7,11,12]$. However, nephrologists have shown little interest in the role that HRQOL plays in mortality in CKD patients [13].

The 36-item Short-Form health survey (SF36) has been validated as a QOL assessment tool for a wide variety of patients, including CKD patients [14-16]. Here, we evaluate HRQOL using the SF36 and assess the impact of HRQOL on mortality in the elderly, who are likely to develop or already have CKD.

\section{Methods \\ Study Participants}

The present study was designed as a population-based, prospective cohort study of health, aging, and common geriatric diseases in a population aged $\geq 65$ years in Seongnam-si, a satellite city of Seoul, Korea. The study design was described in detail elsewhere as an element of the Korean Longitudinal Study on Health and Aging (KLoSHA) [17]. The baseline phase of KLoSHA began in September 2005. The KLoSHA includes two cohorts, one selected from the total population of Seongnam-si (931,019 individuals) and a 6.6\% sample of the population aged $\geq 65$ years. For the elderly sample (Sample-RE), a simple random sample $(1,118$ individuals, $1.81 \%)$ was selected from a list of 61,730 residents aged $\geq 65$ years as of August 1, 2005. The sampled subjects were invited to participate in the study by letter and telephone. Of the 1,118 candidates, 698 agreed to participate in the baseline KLoSHA study. For the "oldest old age" sample (SampleOO), all individuals aged $\geq 85$ years in Seongnam-si $(3,136$ persons) were contacted by letter and telephone, and 302 agreed to participate in the KLoSHA. We enrolled the Sample-OO in addition to the Sample-RE. All participants were Korean. From a random sample of 1,000 par- ticipants, we evaluated 944 who had examined the SF36. All assessments were performed at the Seoul National University Bundang Hospital in Gyeonggi-do, Korea. An independent ethics committee at each participating institution (SNUBH) approved the study protocol (B-0508/ 023-003). The study was conducted in accordance with the Declaration of Helsinki.

\section{Measurements and Definitions}

The investigated clinical parameters included age, sex, ever-drinking, ever-smoking, and a history of hypertension, diabetes mellitus, coronary heart disease (CHD), or cerebrovascular accident (CVA). Systolic blood pressure (SBP) and diastolic blood pressure (DBP) were measured after participants had rested for at least 3 minutes. Numerous laboratory measurements were obtained. Serum measurements included hemoglobin, glucose, total protein, albumin, total cholesterol, triglyceride, high-density lipoprotein (HDL) cholesterol, and creatinine (Cr) levels. Urine measurements included a dipstick test for albumin and measurement of red blood cell (RBC) counts per high-power field by light microscopy. Glomerular filtration rate (GFR) was calculated for 932 participants using the Modification of Diet in Renal Disease (MDRD) Study equation [18].

Patients with one of the following were classed as hypertensive: SBP $\geq 140 \mathrm{mmHg}$, DBP $\geq 90 \mathrm{mmHg}$, or use of antihypertensive medication, irrespective of BP. Diabetes mellitus was defined as a fasting glucose level $\geq 126 \mathrm{mg} /$ $\mathrm{dL}$ or the use of hypoglycemic agents. CHD was defined as self-reported history of angina pectoris, acute myocardial infarction, percutaneous coronary intervention, or coronary artery bypass operation. Proteinuria was defined as albumin $\geq 1+$ and hematuria as an RBC count $>5$ per highpower field. CKD was defined as an estimated GFR <60 $\mathrm{ml} / \mathrm{min} / 1.73 \mathrm{~m}^{2}[19]$.

The HRQOL of subjects was assessed using the Korean version of the SF36 [14,20]. It consists of 36 questions, 35 of which are included on eight multi-item scales: Physical Functioning, Role--Physical, Bodily Pain, General Health, Vitality, Social Functioning, Role--Emotional, and Mental Health. The SF36 assesses physical and mental health components. All-cause mortality data were obtained from the Ministry of Public Administration and Security's national database in June 2009.

\section{Statistical analysis}

All analyses were performed using SPSS software (SPSS version 16.0, Chicago, IL, USA). Data were presented as mean/standard deviations (SD) for continuous variables and as proportions for categorical variables. Demographic and clinical data were described and compared between CKD and non-CKD groups. Differences were analyzed 
using the $\chi^{2}$ test for categorical variables and the Student's $t$ test for non-categorical variables. All subjects were divided into three groups according to tertiles of SF36 scores. The Kaplan-Meier method and the log rank test were used to assess and compare cumulative mortality rates between non-CKD and CKD groups. The unadjusted hazard ratios for all-cause mortality were calculated by the Cox proportional hazard model (model 1), and adjustments were made (model 2). Variables included for adjustments were age, gender, and others that had $P$ values of less than 0.05 in univariate analyses. The hazard ratio for all-cause mortality was calculated after classifying subjects according to the presence of CKD. A $P$ value of less than 0.05 was considered significant.

\section{Results}

\section{Baseline characteristics of participants}

Table 1 shows the patient baseline characteristics. Of the 944 participants, $424(44.9 \%)$ were male and 520 (55.1\%) were female. The mean age was 76 years (range, 65-98 years). The proportions with hypertension and diabetes were $71.1 \%$ and $20.9 \%$, respectively. The mean creatinine level was $1.12 \mathrm{mg} / \mathrm{dL}$ and the mean GFR was 61.1 $\mathrm{ml} / \mathrm{min} / 1.73 \mathrm{~m}^{2}$. Among the participants, $46.6 \%$ had a GFR of less than $60 \mathrm{ml} / \mathrm{min} / 1.73 \mathrm{~m}^{2} ; 8(0.9 \%)$ had a GFR of $15-30 \mathrm{ml} / \mathrm{min} / 1.73 \mathrm{~m}^{2}$, and $2(0.2 \%)$ had a GFR of less than $15 \mathrm{ml} / \mathrm{min} / 1.73 \mathrm{~m}^{2}$. The physical component score was significantly lower in CKD patients than in non-CKD subjects.

Table I: Demographics of participants responding to the baseline Short Form with 36 questions

\begin{tabular}{|c|c|c|c|}
\hline & $\begin{array}{c}\text { CKD (-) } \\
(n=488)\end{array}$ & $\begin{array}{l}\text { CKD (+) } \\
(n=444)\end{array}$ & $\begin{array}{l}\text { Total subjects } \\
(n=944)\end{array}$ \\
\hline Age $\ddagger$ & $74.8 / 8.2$ & $77.4 / 8.9$ & $76.0 / 8.6$ \\
\hline Male gender $(\%)^{\ddagger}$ & 52.9 & 36.5 & 45.1 \\
\hline Hypertension (\%) * & 68.0 & 74.4 & 71.1 \\
\hline Diabetes mellitus (\%) & 20.9 & 20.5 & 20.9 \\
\hline $\mathrm{CHD}(\%)^{\dagger}$ & 4.7 & 10.6 & 7.6 \\
\hline CVA (\%) & 9.2 & 11.0 & 10.1 \\
\hline Ever-drinking (\%)‡ & 45.5 & 32.4 & 39.2 \\
\hline Ever-smoking (\%) * & 43.1 & 35.7 & 39.6 \\
\hline $\mathrm{SBP}(\mathrm{mmHg})$ & $132.6 / 17.8$ & $132.2 / 18.3$ & |32.5/18.1 \\
\hline $\mathrm{DBP}(\mathrm{mmHg})$ & $82.8 / 10.2$ & $82.5 / 11.0$ & $82.7 / 10.6$ \\
\hline \multicolumn{4}{|l|}{ Serum findings } \\
\hline Hemoglobin $(g / d L)^{\ddagger}$ & $13.9 / 1.6$ & $13.6 / 1.4$ & $13.7 / 1.5$ \\
\hline Glucose $(\mathrm{mg} / \mathrm{dL})^{\dagger}$ & | | I.0/28.0 & $106.4 / 20.9$ & |08.9/25.| \\
\hline Total protein $(\mathrm{g} / \mathrm{dL})$ & $7.4 / 0.47$ & $7.5 / 0.46$ & $7.5 / 0.46$ \\
\hline Albumin (g/dL) & $4.09 / 0.27$ & $4.09 / 0.22$ & $4.09 / 0.24$ \\
\hline Total cholesterol $(\mathrm{mg} / \mathrm{dL}) *$ & 199.5/37.5 & $205.7 / 37.6$ & $202.7 / 37.9$ \\
\hline Triglyceride (mg/dL) & |31.|/88.8 & | 37.8/72.9 & |35.0/82.1 \\
\hline HDL cholesterol (mg/dL) & $60.8 / 16.0$ & $59.5 / 14.8$ & $60.2 / 15.4$ \\
\hline Creatinine $(\mathrm{mg} / \mathrm{dL})^{\ddagger}$ & $0.98 / 0.15$ & $1.27 / 0.41$ & $1.12 / 0.34$ \\
\hline eGFR $\left(\mathrm{ml} / \mathrm{min} / \mathrm{l} .73 \mathrm{~m}^{2}\right)^{\ddagger}$ & $70.2 / 8.7$ & $51.0 / 8.1$ & $61.1 / 12.8$ \\
\hline Proteinuria (\%) & 7.4 & 9.4 & 8.4 \\
\hline Hematuria (\%) & 9.9 & I I.3 & 10.8 \\
\hline \multicolumn{4}{|l|}{ SF36 score } \\
\hline Physical functioning ${ }^{\dagger}$ & $56.9 / 27.89$ & $50.6 / 29.60$ & $53.9 / 28.88$ \\
\hline Role---physicalt & $71.1 / 28.46$ & $65.3 / 32.70$ & $68.4 / 30.67$ \\
\hline Bodily pain & 63.1/28.11 & $59.3 / 31.64$ & $61.3 / 29.89$ \\
\hline General health & $43.8 / 21.85$ & $42.7 / 22.05$ & $43.3 / 21.94$ \\
\hline Vitality & $52.3 / 20.56$ & $50.6 / 21.87$ & $51.5 / 21.20$ \\
\hline Social functioning & $79.5 / 23.55$ & $76.4 / 26.80$ & $78.0 / 25.18$ \\
\hline Role---emotional & $81.4 / 26.00$ & $78.3 / 29.36$ & $79.9 / 27.68$ \\
\hline Mental health & $68.6 / 19.52$ & $67.6 / 20.84$ & $68.1 / 20.15$ \\
\hline PCSt & $55.8 / 13.3$ & $53.1 / 14.6$ & $54.5 / 14.0$ \\
\hline MCS & $52.2 / 10.1$ & $51.1 / 11.0$ & $51.7 / 10.5$ \\
\hline Median follow-up (interquartile, months) & $39(35--42)$ & $39(35--4 I)$ & $39(35--42)$ \\
\hline
\end{tabular}

GFR was not estimated in twelve subjects.

$P<0.05,+P<0.01, \neq P<0.001$

Abbreviations: CKD: chronic kidney disease; CHD: coronary heart disease; CVA: cerebrovascular accident; SBP: systolic blood pressure; DBP: diastolic blood pressure; HDL: high-density lipoprotein; eGFR: estimated glomerular filtration rate; SF36: 36-item Short-Form health survey; PCS: physical component summary score; MCS: mental component summary score. 
During the 3-year follow-up period (0-45 months), 104 subjects $(11.0 \%)$ died. Among the clinical and laboratory parameters in Table 1 (excluding the SF36 scores), the mortality rate was associated with age (52.3\% older vs. $47.7 \%$ younger by a median age of 73 years: OR 5.97 (3.50-10.20), $P<0.001)$, ever-smoking (+39.6\% vs. 60.4\%: OR $1.60(1.08-2.35), P=0.018)$, proteinuria (+8.4\% vs. $-91.6 \%$ : OR $2.08(1.20-3.61), P=0.009)$, serum levels of hemoglobin $(1 \mathrm{~g} / \mathrm{dL}$ increase: OR 0.83 (0.74-0.94), $P=0.002)$, total protein ( $1 \mathrm{~g} / \mathrm{dL}$ increase: OR $0.50(0.33-0.75), P=0.001)$, albumin $(1 \mathrm{~g} / \mathrm{dL}$ increase: OR 0.17 (0.10-0.27), $P<0.001)$, total cholesterol $(1 \mathrm{mg} /$ dL increase: OR 0.99 (0.99-1.00), $P=0.004)$, HDL cholesterol ( $1 \mathrm{mg} / \mathrm{dL}$ increase: OR 0.98 (0.97-1.00), $P=0.007)$, and estimated GFR (CKD vs. non-CKD: OR 1.74 (1.172.58), $P=0.006)$. These variables were used for adjustments in multivariate analyses. The 3-year cumulative survival rate was $90.0 \%$ (non-CKD group vs. CKD group: $92.6 \%$ vs. $87.4 \%, P=0.005$ by the log rank test).

\section{Influence of health-related quality of life on all-cause mortality}

Each 10-unit increase on the eight scales was associated with decreased all-cause mortality in study participants after adjustment for multiple variables (Table 2). Univariate analysis showed that groups with high scores of SF36 components (except general health) had greater survival rates than groups with low scores. This trend remained consistent after adjustment (model 2).
Upper tertiles in physical and mental component scores were more highly correlated with improved survival rate than lower tertiles. Using 10-unit increases in physical and mental components, the increase in each score was associated with reduced mortality: the physical component score had an adjusted OR of 0.71 ((0.61-0.84), $P<$ $0.001)$; the mental component score had an adjusted OR of 0.65 ((0.54-0.78), $P<0.001)$.

We divided subjects into two groups on the basis of presence of CKD. Figure 1 and Figure 2 show the Kaplan-Meier curve according to tertiles of SF36 scores and the presence of CKD. Cumulative survival rates according to physical and mental component scores were further separated by the presence of CKD $(P<0.001$ in Figure 1 and Figure 2 by the log rank test). By multivariate analysis (Table 3), the physical component score was associated with allcause mortality, irrespective of CKD. The mental component score was significantly correlated with all-cause mortality in the CKD group; however, the correlation was only marginally significant in the non-CKD group.

\section{Discussion}

Clinicians focus on newer risk factors (e.g., inflammation, oxidative stress, and epigenetic change) as well as traditional risk factors (e.g., atherosclerosis, smoking, and diabetes mellitus) when assessing mortality risk in patients with CKD [21]. It is essential to evaluate non-typical risk factors because the aging society is more heavily con-

Table 2: Hazard ratios for all-cause mortality according to SF36 scores $(n=944)$

\begin{tabular}{|c|c|c|c|c|}
\hline \multirow[b]{2}{*}{ SF36 survey } & \multicolumn{2}{|c|}{ Model Ia } & \multicolumn{2}{|c|}{ Model $2^{b}$} \\
\hline & HR (95\% CI) & $P$ value & HR (95\% CI) & $P$ value \\
\hline \multicolumn{5}{|c|}{ 10-unit increase in SF36 components } \\
\hline Physical functioning & $0.78(0.72--0.83)$ & $<0.001$ & $0.81(0.75--0.89)$ & $<0.001$ \\
\hline Role---physical & $0.85(0.81--0.90)$ & $<0.001$ & $0.90(0.85--0.96)$ & 0.001 \\
\hline Bodily pain & $0.90(0.85--0.96)$ & 0.002 & $0.92(0.86--0.99)$ & 0.020 \\
\hline General health & $0.93(0.85--1.02)$ & 0.123 & $0.90(0.82--1.00)$ & 0.052 \\
\hline Vitality & $0.85(0.77--0.93)$ & $<0.001$ & $0.88(0.79--0.98)$ & 0.018 \\
\hline Social functioning & $0.83(0.78--0.90)$ & $<0.001$ & $0.87(0.81--0.93)$ & $<0.001$ \\
\hline Role---emotional & $0.84(0.80--0.89)$ & $<0.001$ & $0.88(0.83--0.93)$ & $<0.001$ \\
\hline Mental health & $0.85(0.78--0.93)$ & 0.001 & $0.83(0.75--0.91)$ & $<0.001$ \\
\hline \multicolumn{5}{|c|}{ Physical component summary score } \\
\hline Tertile I $(<49.4)$ & I (Reference) & & I (Reference) & \\
\hline Tertile 2 (49.4--6I.7) & $0.46(0.30--0.72)$ & 0.001 & $0.54(0.33--0.87)$ & 0.011 \\
\hline Tertile $3(>61.7)$ & $0.25(0.14--0.43)$ & $<0.001$ & $0.35(0.19--0.64)$ & 0.001 \\
\hline \multicolumn{5}{|c|}{ Mental component summary score } \\
\hline Tertile I $(<49.0)$ & I (Reference) & & I (Reference) & \\
\hline Tertile 2 (49.0--57.0) & $0.68(0.44--1.05)$ & 0.082 & $0.63(0.40--1.01)$ & 0.055 \\
\hline Tertile $3(>57.0)$ & $0.36(0.21--0.6 I)$ & $<0.001$ & $0.39(0.22--0.70)$ & 0.001 \\
\hline
\end{tabular}

a Unadjusted model.

bModel adjusted for age, gender, ever-smoking, proteinuria, serum levels of hemoglobin, total protein, albumin, cholesterol, HDL cholesterol, and estimated GFR.

Abbreviations: SF36: 36-item Short-Form health survey; HR: hazard ratio; Cl: confidence interval. 
Table 3: Stratified analysis of all-cause mortality by the presence of chronic kidney disease

\begin{tabular}{|c|c|c|c|c|}
\hline \multirow[b]{2}{*}{ SF36 survey } & \multicolumn{2}{|c|}{ CKD (-) $(n=488)$} & \multicolumn{2}{|c|}{ CKD (+) $(n=444)$} \\
\hline & HR (95\% Cl) & $P$ value & HR (95\% Cl) & $P$ value \\
\hline \multicolumn{5}{|c|}{ Physical component summary score } \\
\hline Tertile I $(<49.4)$ & I (Reference) & & I (Reference) & \\
\hline Tertile 2 (49.4--6I.7) & $0.44(0.21--0.92)$ & 0.029 & $0.54(0.28--1.05)$ & 0.068 \\
\hline Tertile 3 (>61.7) & $0.23(0.09--0.60)$ & 0.003 & $0.44(0.20--0.98)$ & 0.045 \\
\hline \multicolumn{5}{|c|}{ Mental component summary score } \\
\hline Tertile I $(<49.0)$ & I (Reference) & & I (Reference) & \\
\hline Tertile 2 (49.0--57.0) & $0.67(0.33--1.37)$ & 0.273 & $0.5 \mathrm{I}(0.27--0.99)$ & 0.041 \\
\hline Tertile $3(>57.0)$ & $0.41(0.16--1.05)$ & 0.051 & $0.35(0.17--0.74)$ & 0.006 \\
\hline
\end{tabular}

Model adjusted for age, gender, ever-smoking, proteinuria, serum levels of hemoglobin, total protein, albumin, cholesterol, HDL cholesterol, and estimated GFR.

Abbreviations: CKD, chronic kidney disease; SF36, 36-item Short-Form health survey; HR, hazard ratio; $\mathrm{Cl}$, confidence interval.

fronted with various non-traditional co-morbidities. In the present study, we evaluated the relationship between HRQOL, as measured by the SF36, and all-cause mortality in an elderly population with or without CKD. Both physical and mental components, including each health component, affected all-cause mortality in elderly subjects. This trend was consistent for individuals with CKD. To the best of our knowledge, although HRQOL is known to be related to mortality in patients with end-stage renal disease, no report has been published on the correlation between HRQOL and mortality in patients with CKD. This issue should be kept in mind by nephrologists who may otherwise not be interested in the QOL of CKD patients.

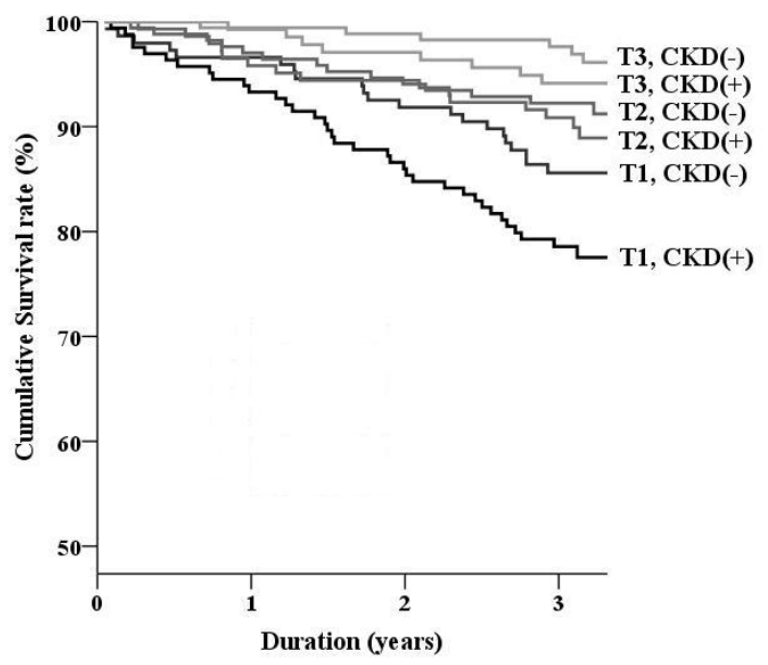

Figure I

Survival curves classified by the presence of chronic kidney disease: physical component score. The KaplanMeier curve is assessed in participants according to the physical component score. Tertiles in physical component score: $\mathrm{TI},<49.4 ; \mathrm{T} 2,49.4--61.7 ; \mathrm{T} 3,>61.7$.
The SF36 is an approved test that is applicable to healthy elderly individuals as well as CKD patients [14-16]. Han et al. also used the SF36 for assessing HRQOL in elderly Koreans ( $\mathrm{n}=219$, aged 73.7 years) [22]. The SF36 scores for each component were similar between Han's cohort and our study cohort, but scores of social functioning, role emotional, and mental health were higher in our cohort. Recently, Mujais et al. reported HRQOL in CKD patients using the Kidney Disease Quality of Life (KDQOL) questionnaire, which combines the generic SF36 instrument with a kidney disease-specific instrument [23]. In their study, the mean physical and mental component scores for stage 3 CKD patients were 40 and 51, respectively. Although comparison between two cohorts is impossible

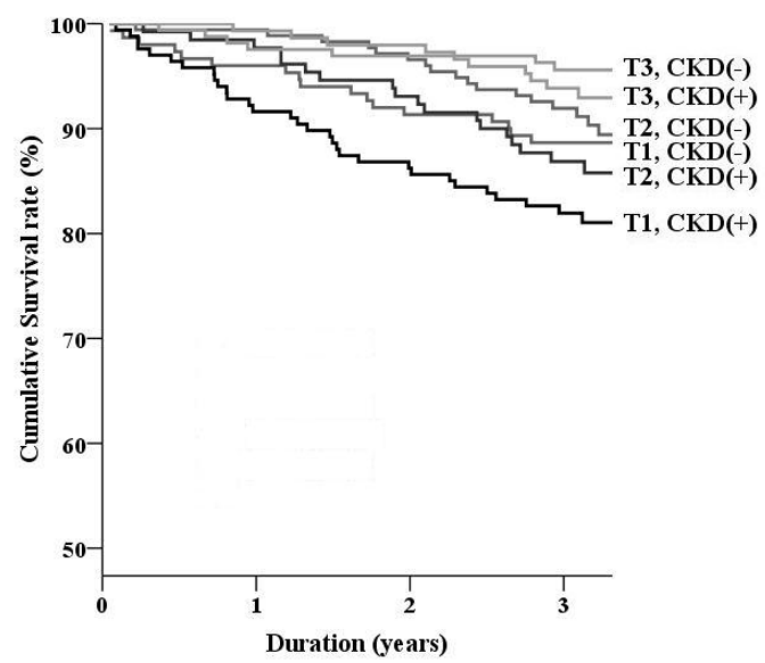

Figure 2

Survival curves classified by the presence of chronic kidney disease: mental component score. The KaplanMeier curve is assessed in participants according to the mental component score. Tertiles in mental component score: TI, <49.0; T2, 49.0--57.0; T3, >57.0. 
because of different baseline characteristics (low proportion of diabetes mellitus, high serum levels of hemoglobin and albumin in our cohort), we assumed that SF36 scores from the randomly sampled design of our cohort could be representative of HRQOL among the elderly in Seongnam-si.

The association between negative self-assessment of health status and mortality in the elderly has been noted for more than 30 years, since Maddox's report [24]. Bernard et al. evaluated the relationship between self-assessment of health status and the subsequent risk of death among the elderly during a 2.5 -year period [12]. When 3,485 elderly subjects were asked, "How would you rate your health at the present time?", the group with an answer of "poor" (the most negative of five possible responses) had an adjusted hazard ratio of 5.5 (4.0-7.5) for mortality compared with those who answered "excellent" (the most positive of five possible responses). Several hypotheses have been proposed to explain the correlation between HRQOL and clinical outcome. For example, a negative self-evaluation of health could stimulate a psychoneuroimmunologic response, reflect the elderly person's accurate self-detection of preclinical changes in body function, or lead to a delay in taking health-protective and maintenance actions $[12,25]$. In some reports, HRQOL has been shown to be related to nutritional factors, such as cholesterol and hemoglobin levels [4,5]. However, it is not fully understood why subjective assessment of health status is strongly correlated with objective clinical outcome after adjustment for chemical markers. Interestingly, the mental component score did not differ between two groups that were divided by an eGFR of 60 $\mathrm{ml} / \mathrm{min} / 1.73 \mathrm{~m}^{2}$. However, the mental component score in the CKD group was a greater predictor of mortality than in the non-CKD group. The reason for the weak correlation between the mental component score and mortality in the elderly without CKD is not clear. It might be because sample number was modest after classification or that elderly individuals without CKD were more strongly affected by the physical component than by the mental component. On the other hand, some studies have reported that a depressed mental state is common and clearly correlated with mortality in patients with end-stage renal disease, consistent with our results $[26,27]$.

The importance of HRQOL in patients with end-stage renal disease is well known. DeOreo et al. examined the SF36 score in 1,000 patients who underwent hemodialysis [28]; the median values of the physical and mental component scores were 37 and 47, respectively. It was revealed that a low SF36 score, particularly a low physical component score, was associated with increased hospitalization and mortality rates. Kalantar-Zadeh et al. also measured SF36 scores in 65 end-stage renal disease patients and found a correlation with hospitalization and mortality; the mental component score and total score had the strongest correlations [5]. Furthermore, these researchers revealed that serum albumin and hemoglobin levels were associated with SF36 scores. However, few studies have investigated CKD patients with reduced renal function (GFR less than $60 \mathrm{ml} / \mathrm{min} / 1.73 \mathrm{~m}^{2}$ ). The present study showed that elderly CKD patients had lower HRQOL scores than subjects without CKD; this reduced HRQOL score was strongly associated with increased allcause mortality after adjustment for traditional risk factors and chemical markers. Furthermore, as shown in Figure 1 and Figure 2, HRQOL further separated the mortality rate according to the presence of CKD. In this regard, we should treat HRQOL and CKD equally.

Although our results are informative, our study is not without limitations. First, because all participants in our cohort were elderly Asian individuals, our results may not be applicable to other ethnic groups or adults aged $<65$ years with CKD. Indeed, Lopes et al. have reported differences in HRQOL among various ethnic groups undergoing hemodialysis [29]. Second, the MDRD equation has not yet been investigated in the Korean population and may not be appropriate for the elderly population. Third, HRQOL was measured only once at the start of the present prospective research; therefore, our data do not show changes during the follow-up period. Fourth, HRQOL was higher than expected (mean value: 54.5 in the physical component; 51.7 in the mental component). However, the purpose of our study was not to evaluate the cut-off point of the SF36 score. Rather, we sought to understand an independent correlation between HRQOL and mortality in CKD patients.

\section{Conclusion}

The present study demonstrated that HRQOL was a strong predictor of all-cause mortality in an elderly Asian population, including subjects with CKD. Although the present study does not reveal the mechanism by which the subjective HRQOL is correlated with the objective outcome of mortality, it would be reasonable to try to improve HRQOL in the elderly and CKD patients to reduce mortality. This is a responsibility of clinicians that will be more important in the aging society as the prevalence of CKD increases. Further studies are needed to ascertain how interventions to increase HRQOL can reduce mortality rates in CKD patients.

\section{Competing interests}

The authors declare that they have no competing interests.

\section{Authors' contributions}

SSH participated in the design of the study and performed the statistical analysis. SSH also wrote this paper. KWK 
participated in the design of the study. KYN collected data and performed the statistical analysis. DWC helped to draft the manuscript. YSK collected data. SK participated in the design of the study. HJC participated in the design of the study and finally approved this paper to be submitted. All authors read and approved this paper.

\section{Acknowledgements}

This work was supported by an independent Research Grant (IRG) from Pfizer Global Pharmaceuticals (grant no. 06-06-039) and a Grant for developing Seongnam Health Promotion Program for the Elderly from Seongnam City Government in Korea (grant no. 800-200502II).

\section{References}

I. World population data sheet of the population reference bureau Geneva. WHO; 2004.

2. Yearbook of Health and Welfare Statistics Seoul, Korea. Korea Ministry of Health and Welfare Statistics 2003.

3. Coresh J, Selvin E, Stevens LA, Manzi J, Kusek JW, Eggers P, Van Lente F, Levey AS: Prevalence of chronic kidney disease in the United States. JAMA 2007, 298( I 7):2038-2047.

4. Chin HJ, Song YR, Lee J], Lee SB, Kim KW, Na KY, Kim S, Chae DW: Moderately decreased renal function negatively affects the health-related quality of life among the elderly Korean population: a population-based study. Nephrol Dial Transplant 2008, 23(9):2810-28I7.

5. Kalantar-Zadeh K, Kopple JD, Block G, Humphreys MH: Association among SF36 quality of life measures and nutrition, hospitalization, and mortality in hemodialysis. J Am Soc Nephrol 200I, I 2(I 2):2797-2806.

6. Mapes DL, Lopes AA, Satayathum S, McCullough KP, Goodkin DA, Locatelli F, Fukuhara S, Young EW, Kurokawa K, Saito A, et al.: Health-related quality of life as a predictor of mortality and hospitalization: the Dialysis Outcomes and Practice Patterns Study (DOPPS). Kidney Int 2003, 64(I):339-349.

7. Kalantar-Zadeh K, Unruh M: Health related quality of life in patients with chronic kidney disease. Int Urol Nephrol 2005, 37(2):367-378.

8. Sytkowski PA, D'Agostino RB, Belanger A, Kannel WB: Sex and time trends in cardiovascular disease incidence and mortality: the Framingham Heart Study, 1950-1989. Am J Epidemiol 1996, I43(4):338-350.

9. Collins AJ, Hanson G, Umen A, Kjellstrand C, Keshaviah P: Changing risk factor demographics in end-stage renal disease patients entering hemodialysis and the impact on long-term mortality. Am J Kidney Dis 1990, 15(5):422-432.

10. Hennekens $\mathrm{CH}$ : Increasing burden of cardiovascular disease: current knowledge and future directions for research on risk factors. Circulation 1998, 97(I I): 1095-I I02.

II. Dorr DA, Jones SS, Burns L, Donnelly SM, Brunker CP, Wilcox A, Clayton PD: Use of health-related, quality-of-life metrics to predict mortality and hospitalizations in community-dwelling seniors. I Am Geriatr Soc 2006, 54(4):667-673.

12. Bernard SL, Kincade JE, Konrad TR, Arcury TA, Rabiner DJ, Woomert A, DeFriese GH, Ory MG: Predicting mortality from community surveys of older adults: the importance of selfrated functional ability. J Gerontol B Psychol Sci Soc Sci 1997, 52(3):SI55-I63.

13. Perlman RL, Finkelstein FO, Liu L, Roys E, Kiser M, Eisele G, BurrowsHudson S, Messana JM, Levin N, Rajagopalan S, et al.: Quality of life in chronic kidney disease (CKD): a cross-sectional analysis in the Renal Research Institute-CKD study. Am J Kidney Dis 2005, 45(4):658-666.

14. Ware JE, Kosinski M, Keller SK, eds: SF-36 Physical and Mental Health Sumary Scales: A User's Manual. Boston: The Health Institute; 1994.

15. Garratt AM, Ruta DA, Abdalla MI, Buckingham JK, Russell IT: The SF36 health survey questionnaire: an outcome measure suitable for routine use within the NHS? BM] 1993, 306(6890): I440-I 444.

16. Diaz-Buxo JA, Lowrie EG, Lew NL, Zhang H, Lazarus JM: Quality-oflife evaluation using Short Form 36: comparison in hemodi- alysis and peritoneal dialysis patients. Am J Kidney Dis 2000, 35(2):293-300.

17. Park JH, Lim S, Lim J, Kim K, Han M, Yoon IY, Kim J, Chang Y, Chang $\mathrm{CB}$, Chin HJ, et al.: An Overview of the Korean Longitudinal Study on Health and Aging. Psychiatry Invest 2007, 4:84-95.

18. Levey AS, Bosch JP, Lewis JB, Greene T, Rogers N, Roth D: A more accurate method to estimate glomerular filtration rate from serum creatinine: a new prediction equation. Modification of Diet in Renal Disease Study Group. Ann Intern Med 1999, I30(6):46|-470.

19. K/DOQI clinical practice guidelines for chronic kidney disease: evaluation, classification, and stratification. Am J Kidney Dis 2002, 39(2 SuppI I):SI-266.

20. Nam BH, Lee SW: Testing the validity of the Korean SF-36 Health Survey. J Korean Society Health Statistics 2003, 28:3-24.

21. Garcia-Lopez E, Carrero JJ, Suliman ME, Lindholm B, Stenvinkel P: Risk factors for cardiovascular disease in patients undergoing peritoneal dialysis. Perit Dial Int 2007, 27(Suppl 2):S205-209.

22. Han CW, Lee EJ, Iwaya T, Kataoka H, Kohzuki M: Development of the Korean version of Short-Form 36-Item Health Survey: health related QOL of healthy elderly people and elderly patients in Korea. Tohoku J Exp Med 2004, 203(3): 189-194.

23. Mujais SK, Story K, Brouillette J, Takano T, Soroka S, Franek C, Mendelssohn D, Finkelstein FO: Health-related quality of life in CKD Patients: correlated and evolution over time. Clin J Am Soc Nephrol 2009, 4(8): I293-I30I.

24. Maddox GL, Douglass EB: Self-assessment of health: a longitudinal study of elderly subjects. J Health Soc Behav 1973, 14(I):87-93.

25. Rakowski W, Mor $\mathrm{V}$ : The association of physical activity with mortality among older adults in the Longitudinal Study of Aging (1984-1988). J Gerontol I992, 47(4):MI22-I29.

26. Kimmel PL, Weihs K, Peterson RA: Survival in hemodialysis patients: the role of depression. J Am Soc Nephrol 1993, 4(I): 12-27.

27. Kimmel PL, Peterson RA, Weihs KL, Simmens SJ, Alleyne S, Cruz I, Veis $\mathrm{JH}$ : Multiple measurements of depression predict mortality in a longitudinal study of chronic hemodialysis outpatients. Kidney Int 2000, 57(5):2093-2098.

28. DeOreo PB: Hemodialysis patient-assessed functional health status predicts continued survival, hospitalization, and dialysis-attendance compliance. Am J Kidney Dis 1997, 30(2):204-2 I 2 .

29. Lopes AA, Bragg-Gresham JL, Satayathum S, McCullough K, Pifer T, Goodkin DA, Mapes DL, Young EW, Wolfe RA, Held PJ, et al: Health-related quality of life and associated outcomes among hemodialysis patients of different ethnicities in the United States: the Dialysis Outcomes and Practice Patterns Study (DOPPS). Am J Kidney Dis 2003, 4 I (3):605-6I5.

\section{Pre-publication history}

The pre-publication history for this paper can be accessed here:

\section{http://www.biomedcentral.com/1471-2369/10/39/pre} pub

Publish with Bio Med Central and every scientist can read your work free of charge

"BioMed Central will be the most significant development for disseminating the results of biomedical research in our lifetime. "

Sir Paul Nurse, Cancer Research UK

Your research papers will be:

- available free of charge to the entire biomedical community

- peer reviewed and published immediately upon acceptance

- cited in PubMed and archived on PubMed Central

- yours - you keep the copyright 